\title{
POLÍTICAS LINGUÍSTICAS E A LÍNGUA DE SINAIS BRASILEIRA
}

\section{LINGUISTICS POLICIES AND THE BRAZILIAN SIGN LANGUAGE}

\author{
POLÍTICAS LINGÜÍSTICAS Y LA LENGUA DE SEÑALES \\ BRASILEÑA
}

\author{
Josmar Gonçalves Júnior* \\ Yasmin Galvani Tonete Dórea** \\ Marcos KluberKogut ${ }^{* * *}$ \\ Luiz Cláudio da Silva Souza****
}

\section{Resumo}

Este estudo tem como objetivo apresentar algumas reflexões sobre as políticas linguiísticas e a Língua Brasileira de Sinais (Libras). Também aborda o plurilinguismo, na tentativa de identificar a relação entre línguas e poder. O que justifica tal empreitada é a percepção da necessidade de criação de políticas linguísticas que promovam a difusão da Libras, para que mais pessoas possam conhecê-la. A pesquisa foi realizada por meio de entrevistas com alunos surdos, estudantes do curso de Letras: Libras da Faculdade de Letras da Universidade Federal de Goiás (UFG), Goiânia. Espera-se que as considerações apresentadas possam contribuir para novas reflexões sobre 0 plurilinguismo, que é um fato em vários países, dentre os quais o Brasil.

Palavras-chave: Plurilinguismo. Libras. Políticas linguísticas.

\footnotetext{
* Graduado no Curso de Letras: Libras da Faculdade de Letras da Universidade Federal de Goiás (UFG), Goiânia. E-mail: josmar.goncalves.junior19@gmail.com

** Graduada no Curso de Letras: Libras da Faculdade de Letras da Universidade Federal de Goiás (UFG), Goiânia. E-mail: yasmingavani@gmail.com

*** Mestre em Linguística pela Universidade Federal de Santa Catarina (UFSC). Professor do Curso de Letras: Libras e do Curso de Letras: Tradução e Interpretação em Libras/Português da Faculdade de Letras da Universidade Federal de Goiás (UFG), Goiânia. E-mail: marcoskkogut@ gmail.com

${ }^{* * * *}$ Mestre em Linguística Aplicada pela Universidade Federal do Rio de Janeiro (UFRJ). Professor do Curso de Letras: Libras e do Curso de Letras: Tradução e Interpretação em Libras / Português da Faculdade de Letras da Universidade Federal de Goiás (UFG), Goiânia. E-mail: 1.claudio.ufg@gmail.com
} 


\section{Considerações iniciais}

A palavra "política", de acordo com Noberto Bobbio (2000, p.54) origina-se do termo grego "politikós", o qual, por sua vez, deriva de "polis", a cidade-estado grega, com o significado: "o que se refere à cidade”, ou seja, o que é urbano, civil, público, assim como, o que é sociável e social. Coube a Aristóteles a missão de ampliar o termo, dando-lhe o sentido de "arte" ou de "ciência" do governar. Na era moderna, a expressão "ciência do Estado" foi aos poucos se modificando, sendo substituída por "doutrina do Estado", ou ainda, "ciência política", até ser empregada para descrever atividades relacionadas ao Estado. Sendo assim, os conceitos sobre "política" estão profundamente relacionados ao poder do Estado.

As políticas linguísticas surgiram na década de 1960 como uma área de estudos que cuidava das relações entre o poder e as línguas, visando estudar as decisões políticas em relação às línguas e aos seus usos na sociedade. Durante um longo período, as políticas linguísticas foram evidenciadas como uma incumbência unicamente do Estado, sendo conhecidas nos meios científicos com a denominação de "planificação linguística”, referindo-se essa expressão às ações de agentes sociais, ou da sociedade civil, voltados para a existência, a conservação e a dissipação das línguas não-oficiais, as quais não são consideradas momentaneamente pelo Estado. Essa intervenção estatal nas situações lingüísticas não é uma característica da contemporaneidade, uma vez que sempre se tentou prescrever e definir o uso adequado da língua. Em Portugal, na época do Brasil Colônia, ocorreu a implantação de uma política linguística, emitida a partir de Lisboa pelo Marquês de Pombal (1699-1782), que não levou em consideração as línguas faladas no Brasil daquela época.

Ao refletir sobre conceitos de poder, Bobbio (2000) aponta três categorias: poder econômico, poder ideológico e poder político. O primeiro privilegia o direito de posse sobre os meios de produção; o segundo assenta-se na influência das ideias de grupos que representam o poder dominante e o terceiro, o poder político, tem a máquina burocrática e todos os instrumentos do Estado, inclusive as armas, a seu dispor.

Conceitos de política e poder também podem ser aplicados às relações entre as línguas. Na história das línguas no Ocidente, há muitos exemplos de relações de poder e de estabelecimento de um status linguístico, maior ou menor, dependendo da influência da língua. O status linguístico depende das relações de força entre os grupos sociais que 
utilizam determinadas línguas, ou ainda, da percepção que os indivíduos têm dessas relações.

A relevância da língua advém da relevância cultural de seus usuários e de outras circunstâncias, entre as quais, o prestígio econômico. O conjunto de aspectos relevantes, positivos de uma língua, determina o seu "poder inato". As diferentes fontes de poder de uma língua fazem com que se sobreponha a outras e evidenciam as diferenças quando esta se coloca em contato com outra. Para que uma língua alcance um status que lhe garanta poder e influência, são necessárias algumas medidas que possam conduzi-la a um lugar de prestígio na sociedade, atendendo às determinações e às aspirações da comunidade que a utiliza.

Nas disputas por poder e soberania que sempre ocorreram entre os povos, a língua foi um dos instrumentos de domínio que uma nação usava sobre outra. As nações colonizadoras impunham a sua língua aos colonizados que, geralmente, se submetiam ao uso da língua de seus dominantes. Durante o período em que foi colônia de Portugal, o Brasil foi perdendo, pouco a pouco, sua característica plurilíngüe, devido à disseminação da língua portuguesa, imposta como língua oficial, sobrepondo-se às diversas línguas de origem indígena e africana, faladas por boa parte da população. $O$ predomínio da língua portuguesa no território dominado por Portugal se consolidou quando, segundo Almeida (1997) o Marquês de Pombal promulgou a Lei do Diretório dos Índios, que vigorou, entre 1757 e 1798, que transformava os aldeamentos indígenas em vilas, com escolas onde se ensinava somente o português, sendo proibido o uso de outros idiomas.

Conforme observa Acosta (2012), o Brasil conheceu 35 línguas de imigrantes. Algumas delas, como a espanhola, a italiana, a inglesa, a alemã e a francesa, chegaram a ocupar o espaço escolar. Atualmente, entre as que mais têm presença no cotidiano escolar estão o inglês e o espanhol. A justificativa para o seu estudo é que são necessárias para que os alunos possam interagir com o mundo, tendo em vista o número expressivo de seus usuários e seu status internacional.

Em 2010, por meio do Decreto $\mathrm{n}^{\circ} 7.387$, foi instituído Inventário Nacional da Diversidade Linguística. Sob a gestão do Ministério da Cultura, o Inventário foi criado com a função de se tornar um "instrumento de identificação, documentação, reconhecimento e valorização das línguas portadoras de referência à identidade, à ação e à memória dos diferentes grupos formadores da sociedade brasileira" (BRASIL, 2010). 
Em seus artigos iniciais, é possível observar que a proposta do Ministério da Cultura é valorizar as línguas utilizadas no Brasil e incorporá-las ao planejamento linguístico do país:

Art. $2^{-}$As línguas inventariadas deverão ter relevância para a memória, a história e a identidade dos grupos que compõem a sociedade brasileira.

Art. 3ํ A língua incluída no Inventário Nacional da Diversidade Linguística receberá o título de "Referência Cultural Brasileira", expedido pelo Ministério da Cultura(BRASIL, 2010).

O documento afirma que as línguas incluídas receberão o título de "Referência Cultural Brasileira", no entanto, fica a dúvida: será que esse título supre o respeito que deve ser dado às variedades linguísticas? Se as políticas lingüísticas, defendidas pelos governos do Brasil, firmam seus alicerces exclusivamente sobre a norma culta da língua portuguesa, pode-se concluir que a democracia brasileira não abrange as línguas, especialmente quando prevalece a concepção de que a norma culta é mais privilegiada, em relação às demais variantes e às línguas indígenas. Nesse caso, vive-se em uma democracia que privilegia poucos em detrimento de muitos? Com diferenças determinadas não só por fatores econômicos, mas também linguísticos, essa circunstância sugere o que Bagno (2005) denomina "preconceito linguístico" e exclusão cultural.

Outro exemplo de país plurilíngue e pluricultural é Moçambique. Menezes (2013) observa que, devido a fatores históricos e sociais, há várias línguas nativas, convivendo com outras línguas de imigrantes que se instalaram no país. Em Moçambique é possível ao falante optar por códigos diferentes. Segundo Gonçalves (2012), a maioria das línguas faladas em Moçambique é de origem bantu, mas a língua oficial do país, desde sua independência, em 1975, é o Português. O país tem 43 línguas, chamadas "línguas nacionais", o português e a língua de sinais. Conforme o Censo de 2007, cujos resultados foram publicados pelo Instituto Nacional de Estatística de Moçambique. Com o estatuto de língua oficial, o português é falado por mais da metade da população como segunda língua. Segundo o site A Língua Portuguesa, que se baseia em dados do Censo de 1997: 
[...] o português era falado por cerca de $25 \%$ da população e constituía a língua materna de pouco mais de $1 \%$ dos moçambicanos. Os dados do Censo de 1997 indicam que a percentagem atual de falantes de Português já é de $39,6 \%$, que $8,8 \%$ usam o português para falar em casa e que $6,5 \%$ consideram o português como sua língua materna. A vasta maioria das pessoas que têm a língua portuguesa como materna reside nas áreas urbanas do país, e são os cidadãos urbanos, principalmente, que adotam o português como língua de uso em casa. No país como um todo, a maioria da população fala línguas do grupo bantu. A língua materna mais frequente é o emakhuwa (26.3\%); em segundo lugar está o xichangana (11.4\%) e em terceiro, o elomwe (7.9\%) (MEDEIROS, 2006).

Como o português é a língua oficial de Moçambique, os órgãos públicos poderiam fazer suas divulgações e publicações em língua portuguesa, contudo, o país ainda se encontra em processo de adaptação, tendo em vista que em 1975, ano da independência moçambicana, grande parte da população não utilizava o idioma oficial. Esse processo linguístico pode durar anos, até que o conhecimento do português se estenda à maior parte da população. Vale ressaltar que a escolha da língua portuguesa como língua oficial foi uma maneira de facilitar a comunicação entre os habitantes do país. Face ao processo de identidade nacional ou nativação, decorrente da influência das línguas nacionais, o português de Moçambique apresenta características diferentes do português europeu, do brasileiro e de outras nações que adotaram essa língua.

No que tange ao Brasil, embora o país seja considerado monolíngue, em todo o seu território são falados mais de 200 línguas, das quais 170 são indígenas. De acordo com Quadros (2010), essas línguas são chamadas "autóctones" e as outras 30, de descendentes de imigrantes, são as chamadas "alóctones". Isso significa que, como a maioria dos países do mundo, o Brasil é um país plurilíngue. Em relação à situação linguística do Brasil, Quadros ressalta ainda que o país "teve uma política de extermínio linguístico em favor da legitimação de uma única língua, a língua portuguesa; portanto, com um planejamento pautado em uma política linguística que favoreceu o monolinguismo" (2010, p. 16).

$\mathrm{Na}$ verdade, o Brasil continua, na prática, sendo um país plurilíngüe, em virtude das línguas faladas em território nacional. Dentre as diferentes línguas usadas no país, tem-se a Língua Brasileira de Sinais (Libras), reconhecida como língua oficial do Brasil, a partir da Lei $\mathrm{n}^{\mathrm{o}} 10$ 436, do ano de 2002, e regulamentada pelo Decreto 5626, de 2005. Essa legislação apresenta, além de preceitos, um delineamento linguístico, para que a 
Língua Brasileira de Sinais possa ser reconhecida, difundida, ensinada e, acima de tudo, utilizada no país.

Entre as medidas propostas, está prevista a inclusão da Libras em diferentes espaços e contextos da sociedade, assegurando para a população surda do Brasil o acesso à educação bilíngue. Em escolas bilíngües o aluno teria aulas em Libras para aprendizado do português como segunda língua. Concomitantemente, propõe-se ainda a inclusão de disciplinas de Libras nos currículos de todos os cursos de licenciatura, bem como do curso de fonoaudiologia. As escolas públicas também deveriam ofertar a disciplina Libras no contexto escolar.

O Decreto dedica um capítulo à formação e capacitação dos profissionais que irão trabalhar com a Língua Brasileira de Sinais, propondo a criação de cursos como o de Letras: Libras; Pedagogia Bilíngue, e ainda, Letras: Tradução e Interpretação. Também regulamenta os direitos dos indivíduos surdos ao acesso de informações e atendimento público em sua língua materna, a Libras, resultando daí vários desdobramentos, a partir da Lei 10436 de 2002.

Uma pesquisa realizada na Universidade Federal de Goiás, no período entre agosto e novembro de 2016, contou com a participação de 30 alunos da comunidade surda universitária do curso de Letras: Libras. Os participantes foram homens e mulheres, com idade média de 25 anos, surdos e fluentes em línguas de sinais. Desses alunos, 20 deles aprenderam libras em torno dos 7 anos de idade, como resultado da omissão do Estado nos cuidados com a educação pré-escolar de surdos e da má orientação dada aos pais por profissionais da saúde.

Dois desses alunos são filhos de pais surdos, que tiveram acesso à Língua Brasileira de Sinais quando bebês, e os oito alunos restantes só tiveram acesso à Libras após os 12 anos de idade, depois de passarem por traumas com fonoaudiólogos e tratamentos invasivos, como o implante coclear.

Para coleta dos dados necessários foi feita uma pesquisa sobre as políticas linguísticas para Libras, considerando a média da idade de acesso à língua. A pesquisa tinha duas perguntas:

1- Quais políticas necessárias para melhorar a qualidade de vida dos surdos? 
2- Quais áreas têm sido pouco contempladas com as políticas linguísticas para os surdos?

Quanto à primeira questão, sobre as políticas necessárias para melhorar a qualidade de vida dos surdos, dos 30 alunos entrevistados, 20 não sabiam o significado da expressão “políticas lingüísticas”. Foi necessário apresentar alguns dados sobre o tema e, após as explicações, a resposta dos pesquisados foi sobre a necessidade de se cobrar o conhecimento de Libras em concursos públicos. Dentre as profissões citadas como as mais importantes para a inclusão social dos surdos estão: bancários, policiais, professores, médicos, enfermeiros e dentistas.

Entre os 10 alunos que tinham conhecimento sobre o significado de "políticas lingüísticas", 5 deram a mesma resposta, destacando a importância de que os cursos de licenciatura tivessem mais horas em suas grades para a disciplina de Libras. Foi sugerido algo em torno de 3 ou 4 semestres da disciplina.Esses alunos também destacaram que a falta de informações sobre a Libras no ambiente universitário afeta profundamente o desenvolvimento do aluno surdo em sala de aula, tendo em vista que o intérprete, na maioria das vezes, não tem o conhecimento do conteúdo e da metodologia de ensino do professor. Também foi apontado que os surdos, ao se dirigirem aos consultórios médicos ou dentários, não podem sempre estar ao lado de alguém da família, ou levar um intérprete, pois algumas vezes querem conversar particularmente com o profissional de saúde. No decorrer da pesquisa, 25 entrevistados disseram acreditar que, se a Libras for realmente difundida, como determina a lei, o surdo não vai depender de terceiros para a realização de atividades cotidianas; 5 alunos não souberam ou não quiseram responder.

No que diz respeito ao segundo questionamento, acerca das áreas que têm sido pouco contempladas com a política linguística para surdos, 20 alunos acreditam que as áreas da saúde, da segurança e também a comercial (bancos, lojas, shoppings, cinemas e supermercados) precisam se preparar melhor para atender os surdos. No que diz respeito ao mercado de trabalho, esse também não se adaptou, preferindo, muitas vezes, ignorar o surdo. De acordo com as manifestações espontâneas de alguns entrevistados, 2 ressaltaram que não conseguem assistir a filmes nacionais, pois as empresas não disponibilizam legendas; 5 disseram ter deixado de comprar em alguma loja por não conseguirem ser atendidos e afirmaram que não houve interesse do vendedor em se comunicar, ou tentar entender do que necessitavam; 5 acreditam que o surdo só terá o 
seu espaço assegurado quando a sociedade se conscientizar e aprender a respeitar suas diferenças. Em um universo de 30 entrevistados, 15 alunos disseram que, em ambientes como bancos e shoppings, se sentem mal diante de situações em que não conseguem se comunicar.

No que diz respeito à segurança, um dos alunos entrevistados relatou que os policiais também necessitam de mais preparo, em relação à comunicação com surdos. Relatou um assalto, do qual foi vítima, e da dificuldade de ser compreendido na delegacia, onde deveria registrar a ocorrência. O aluno ressaltou que os policiais gritavam, acreditando que ele poderia ouvir. Só depois de algum tempo lhe deram um pedaço de papel e uma caneta para que pudesse escrever sobre o ocorrido. O escrivão, que registrava a ocorrência, não entendeu o que estava escrito, uma vez que o português escrito do surdo tem características diferentes do português escrito pelo ouvinte. A situação se resolveu quando o surdo, cansado, pediu uma ligação telefônica para que chamassem a sua mãe e, somente com a sua chegada, foi possível lavrar o Boletim de Ocorrência.

Após a pesquisa, verificou-se que, os fatores de variação de idade para aquisição da Libras, assim como a falta de acesso do surdo ao aprendizado de sua língua materna,não foram tão significantes para o resultado. Após poucos anos de exposição à Libras, os surdos, naturalmente, se tornam fluentes.

\section{Considerações finais}

Em diferentes momentos da história, a língua se mostrou mais do que um meio de comunicação, revelando-se um jogo de valores e interesses que beneficiava metrópoles, países e classes sociais mais privilegiadas. Nesses processos históricos de dominação e submissão, é possível afirmar que ocorrem situações de desvalorização cultural, de desrespeito a línguas consideradas menos privilegiadas. Por outro lado, são valorizadas as línguas que adquirem status nas relações e no mercado internacional.

Isso ocorreu com diversas línguas, tal como o inglês, o francês, o espanhol e o português, que foram impostas aos povos colonizados. Atualmente, o inglês e a cultura norte-americana, por se tratar de uma grande potência, se impõem a países menos desenvolvidos, tornando de grande importância o aprendizado da língua inglesa, utilizada internacionalmente para negociações. Esse status linguístico do inglês é 
reconhecido internacionalmente, tendo em vista que os Estados Unidos da América são uma grande potência comercial e militar. Atualmente, o inglês é a terceira língua mais falada no mundo, perdendo apenas para o mandarim e o espanhol.

No que diz respeito à Língua Brasileira de Sinais, nota-se que houve um grande avanço, se compararmos ao século anterior, quando os surdos eram excluídos da sociedade e, muitas vezes, submetidos a tratamentos médicos desnecessários. Atualmente, o surdo ainda se depara com dificuldades e preconceitos, embora nada se compare ao seu passado obscuro e doloroso.

Entre as expectativas dos alunos surdos consultados, está a expansão, para todo o território nacional, do ensino da Língua Brasileira de Sinais nas escolas brasileiras. A Libras deveria ser aprendida por todos, para que o surdo obtenha completa independência, podendo sair de casa sem se preocupar se será compreendido ou se deve adequar o seu horário para obter auxilio de interpretação. Mas esse é um processo em andamento. Muito já foi feito e inúmeras são as conquistas, porém ainda há o que fazer. É muito importante que a comunidade surda continue ativa, discutindo suas necessidades e, acima de tudo, expandindo e valorizando a sua língua materna.

\begin{abstract}
This study aims at presenting some reflections on the language policies and the Brazilian Sign Language (Libras). It also addresses issues of plurilingualism in an attempt to identify the relationship between languages and power. What justifies this endeavor is the perception of the need to create linguistic policies that promote the diffusion of Libras, so that more people can take notice of it. The research was conducted through interviews with deaf students of the Libras Course of the Federal University of Goiás (UFG), Goiânia. It is expected that the considerations presented contribute to new reflections on plurilingualism, which is a fact in several countries, among which, Brazil.
\end{abstract}

Key-words: Plurilingualism. Libras. Language policies.

\title{
Resumen
}

Este estudio tiene el objetivo de exponer algunas reflexiones sobre las políticas lingüísticas y la Lengua Brasileña de Señales (LIBRAS). También se ocupa de cuestiones de plurilingüismo, en el intento de identificar la relación entre lenguas y poder. Lo que justifica este trabajo es la percepción de la necesidad de políticas lingüísticas que promuevan la difusión de la LIBRAS, para que más personas puedan conocerla. La investigación fue realizada por medio de entrevistas con alumnos sordos, 
estudiantes del curso de Letras: Libras de la Universidad Federal de Goiás. Se espera que las ideas presentadas puedan contribuir para nuevas reflexiones sobre el plurilingüismo, que es un hecho concreto en varios países, entre los cuales está Brasil.

Palabras clave: Plurilingüismo. LIBRAS. Políticas lingüísticas.

\section{Referências}

ACOSTA, J. D.. "Políticas Linguísticas: do Plurilinguismo ao Monolinguismo - Existe democracia linguística?". Junipampa: Jornal Universitário do Pampa. Bagé: UNIPAMPA, 2012. Disponível em: http://www.junipampa.net/2012/11/politicaslinguisticas-do.html . Acesso em: 22 abr. 2018.

ALMEIDA, Rita Heloísa. O diretório dos índios; um projeto de civilização no Brasil do século XVIII. Brasília: UnB, 1997.

BAGNO, Marcos. Preconceito lingüístico: o que é, como se faz. São Paulo: Edições Loyola, 2005.

BOBBIO, Norberto. Teoria Geral da Política: a filosofia política e as lições dos clássicos. Tradução de Daniela BeccacciaVersiani. Rio de Janeiro: Campus, Elsevier, 2000 .

BRASIL. Lei $\mathrm{n}^{\circ}$ 10.436, de 24 de abril de 2002. Dispõe sobre a Língua Brasileira de Sinais - Libras e dá outras providências. Brasília, DF, 25 abr. 2002. Disponível em: http://www.planalto.gov.br/ccivil_03/leis/2002/L10436.htm. Acesso em: 10 abr. 2018.

Decreto $\mathrm{n}^{\circ}$ 5.626, de 22 de dezembro de 2005. Regulamenta a Lei $\mathbf{n}^{\mathbf{0}}$ 10.436, de 24 de abril de 2002, que dispõe sobre a Língua Brasileira de Sinais Libras. Brasília, DF, dez. 2005. Disponível em: http://www.planalto.gov.br/ccivil_03/_ato20042006/2005/decreto /d5626.htm Acesso em: 10 abr. 2018.

Decreto $\mathrm{N}^{\circ} 7.387$, de 9 de dezembro de 2010. Institui o Inventário

Nacional da Diversidade Linguística e dá outras providências. Brasília, 2010.

Disponível em: http://www2.camara.leg.br/legin/fed/decret/2010/decreto-7387-9-

dezembro-2010-609640-publicacaooriginal-130955-pe.html Acesso em: 10 mai 2018.

MEDEIROS, A.. A Língua Portuguesa. DCA-UFRN, 2006. Disponível em: http://www.linguaportuguesa.ufrn.br/pt 3.4.d.php Acesso em 16 abr. 2018.

MENEZES, L. J.. "Plurilinguismo, Multilinguismo e Bilinguismo: Reflexões sobre a Realidade Linguística Moçambicana". Revista PERcursos Linguísticos. V.3, N. 7 Vitória: UFES, 2013. Disponível em:

http://periodicos.ufes.br/percursos/article/view/4589/4578. Acesso em: 15 abr. 2018.

GONÇALVES, P., Lusofonia em Moçambique: com ou sem glotofagia?.II Congresso Internacional de Linguística Histórica, São Paulo, 2012.Disponível em 
http://www.catedraportugues.uem.mz/lib/docs/lusofonia_em_mocambique.pdf Acesso em: 15 abr. 2018.

MOÇAMBIQUE, Instituto Nacional de Estatística. 2007. Disponível em: http://www.ine.gov.mz/. Acesso em 15 abr. 2018.

QUADROS, R. M.; CAMPELLO, A. R. S.. "Constituição política, social e cultural da Língua Brasileira de Sinais”. In: VIEIRA-MACHADO, L. M.; LOPES, M. C.. (Org.). Educação de Surdos: Políticas, Língua de Sinais, Comunidade e Cultura Surda. Santa Cruz: EDUNISC, 2010, p. 15-47.

\footnotetext{
' De acordo com o Blog Universo Traduções, o ranking das línguas mais faladas do mundo é: Mandarim, 1,3 bilhão - China, Malásia e Taiwan; Espanhol, 427 milhões - Espanha e Américas; Inglês: 339 milhões- Eua, Reino Unido, Partes da Oceania. Disponível em: http://universotraducoes.com/pt/linguasmais-faladas-no-mundo/ Acesso em: 15 abr.2018.
} 